\title{
Technology Neutrality: Exploring The Interaction between International Mobile Telecommunication and National Spectrum Management Policies*
}

\begin{abstract}
This paper reviews ITU-R actions with respect to IMT standardization, and how these actions affect national spectrum management decisions such as those related to technology neutrality and selection based on data collected from 52 interviews.

Our analysis demonstrates that the IMT standardisation activities do not explicitly influence the decision of the regulator on the adoption of technology neutrality. They do, however, contain a range of positive (encouraging) and negative (discouraging) perspectives that shape the regulator's views on technology neutrality. are two contrasting views on whether there is mutual influence between the IMT definitions within the ITU-R, and $3 \mathrm{G}$ and $4 \mathrm{G}$ market definitions.

Nationally IMT standardisation has largely no influence on the discrimination between mobile technology generations (e.g. 3G, 4G). The IMT spectrum identification has positive influences on selecting technologies from the IMT family.
\end{abstract}

Keywords: IMT, Technology neutrality, ITU-R, Technological choices

* The authors are solely responsible for the opinions expressed in this article. 


\section{Introduction}

The rapid growth in wireless services and the increasing demand for mobile broadband have led to calls for the re-examining of how radio spectrum, a critical component in the delivery of wireless services, is managed (Cave, Foster, \& Jones, 2006). This has led several commentators to review the traditional approach to national spectrum management, which is commonly referred to as 'command and control', and which has been criticised for creating an artificial scarcity due to inefficient utilisation rather than a shortage of spectrum (Wellenius \& Neto, 2005).

A key disadvantage of the 'command and control' is the regulator's predetermination of technologies to be deployed by operators (OECD, 2006). Having said that, there are several alternatives to 'command and control' that are compatible with technology neutrality (Chaduc \& Pogorel, 2008).

One alternative approach to overcome these challenges and to reform national spectrum management policies is spectrum market. Such approach calls for treating spectrum assignments in a similar way to other property rights and allowing spectrum usage flexibility so that service and technology neutrality occur (Coase, 1959; Hazlett, 1998a).

The market approach is based on allocation flexibility, technology neutrality, exclusive property rights and market-based assignment (Chaduc and Pogorel, 2008). In such approach it is argued that private operators are more knowledgeable of the market and will choose the optimum service to the consumers (Hazlett, 2001). The origin of market approach could be traced back to the dilemma that the FCC faced in choosing between three different standards for transmitting systems of colour television signals in 1951 (Herzel, 1951). The FCC performed what can be called a technical beauty contest and adopted only one standard.

Herzel (1951) suggested a revolutionary solution at that time to use an auction to choose among the competing standards. Herzel (1998) explains afterwards that his main concern at that time was not using auction as much as having packages of spectrum rights and obligations. Smythe (1952) defended the FCC position at that time by explaining that the different spectrum users should be treated differently according to their activities (especially governmental agencies) and therefore bidding cannot be used as the mechanism to choose among them. Herzel (1952) responded by arguing that radio spectrum is similar to any other object (e.g. equipment) that users compete for.

Coase (1959) supported Herzel's argument in his seminal contribution 'the federal communications commission' and suggested that spectrum assignments should be treated in a way similar to property rights. Coase argued also that the aim of the regulator should be to maximise the output and not to minimise the interference and that interference should not be an issue as long as the gain from it is much more than the harm it produces. Coase (1960) generalised his argument afterwards in his Nobel prize article 'the problem of social cost' and suggests an approach toward dealing with harmful effects on others that is based on comparing the total social product yielded by alternative social arrangements. Therefore, interference by one user against the other could be allowed if society benefits are much more rather than in the case of delimiting interference.

At the international level, the ITU-R is the administrative body responsible for managing spectrum matters that have global influence through the ITU-R Radio 
Regulations (RR) and the ITU-R resolutions, recommendations and reports. The ITU$\mathrm{R} R \mathrm{R}$ have international treaty status and they are binding for all the ITU-R countries (Maitra, 2004). In contrast, ITU-R recommendations do not have a legal status similar to the ITU-R RR unless they are incorporated by reference in the RR (Maitra, 2004).

The ITU-R has been involved in two aspects of personal mobile communication systems under the label IMT: firstly, defining the standards and spectrum identification related to these systems as a response to the lack of interoperability between 2G standards (Maitra, 2004); and, secondly, the need for global roaming (McLean Foster \& Co., 2013). In particular, the ITU-R work on the International Mobile Telecommunication (IMT) standards has resulted in having six and two terrestrial radio interfaces that are part of the IMT-2000 (ITU, 1998) and IMT-Advanced (Funk, 1998) family of standards respectively. In addition, the IMT standardisation process has been associated with identifying spectrum bands by the ITU-R for the use of IMT radio interfaces to enable global roaming (ITU-R, 2017).

However, it is not clear what is the influence of the international activities in the ITU-R that are related to mobile technologies on national regulators' decisions with regard to adopting these technologies. More specifically, while most of the literature that addresses technology neutrality focuses on national circumstances such as market structure and auction design (ITU-R, 2015b), the influence of IMT standardisation activities in the ITU-R is, however, largely overlooked. Although the ITU-R recommendations on IMT are not by nature binding, they are usually respected by ITU-R member states and are taken quite seriously by some administrations (e.g., Japan). This is not to suggest that mobile telecommunication standards published by organisations such as ETSI and 3GPP are irrelevant, but rather to highlight the central and arguably influential role played by the IMT.

With this in mind, this paper seeks to shed light on how the IMT and national radio spectrum management policies interact with regards to technology neutrality. To understand this relationship, four questions are explored:

1. What is the influence of IMT standardisation on technology selection and neutrality at the national level?

2. What is the influence of IMT standardisation on perspectives regarding mobile technology generation definition and determination (e.g. 2G, 3G, 4G)?

3. What is the influence of IMT standardisation on discrimination between mobile technology generations and being biased against or in favour of a particular technology?

4. What is the influence of IMT spectrum identification on technology selection and technology neutrality?

With this in mind, the rest of the paper is organised as follows: The following section explores mobile technology selection on the national level, and Section 3 addresses the activities related to personal mobile standardisation in the ITU-R. Section 4 highlights the methodology adopted for this paper. Sections 5 to 8 examine the interaction between IMT and national spectrum management policies in terms of decisions related to technology neutrality and technology selection, the influence of IMT standardisation on the perception on $3 \mathrm{G}$ and $4 \mathrm{G}$ technologies and influence of IMT spectrum identification on regulator's decision regarding technology selection and technology neutrality respectively. Conclusions are drawn in Section 9.

\section{Technology selection}


Technology selection is one of the main elements of any spectrum management approach where selection of technologies could be neutral, restricted to standardised technologies or selective of specific technologies (ITU-R, 2001b, 2007c). Standardisation refers to the level of specification of allocated services such as transmitter power, and channelization whereas, technology neutrality is defined by (Ali, 2009; Bohlin, 2012; Frullone, 2007; Kamecke \& Korber, 2006) as the minimum applied constraints while ensuring that interference is appropriately addressed. Another definition suggests that true technology neutrality implies defining conditions without any biased assumptions (Chaduc \& Pogorel, 2008; Freyens, 2009).

There are pros and cons associated with limiting the choice of technology to standardised ones (Foster, 2008). The main advantage of standardisation is that it allows large production scale, which reduces the cost of the equipment. Moreover, the benefits of standardisation include avoiding harmful interference and promoting interoperability between terminals and public networks. On the other hand, standardisation may lead to locking in an inferior standard and delays in the introduction of new equipment. An example of the failure in selecting the right technology is the enhanced radio messaging system (ERMES), which was an initiative to create a Europe-wide mobile messaging system that ended without any significant deployments of the technology (Whittaker, 2002). In fact, one of the main providers of ERMES, Ericsson, considers the standard to be a failure (Indepen and Aegis Systems, 2004; London Economics, 2008; Pogorel, 2007). Some may consider that the standard largely failed even before regulators had to make choices.

It is argued that, in general, governments are not successful when it comes to selecting winning standards due to the absence of the industry commercial motivation to identify efficient technologies (Cave, 2002).

With regards to personal mobile telecommunication, there have always been tensions between different technologies. For instance, in the $2 \mathrm{G}$ era there was a global competition between GSM and CDMA standards, with the former winning in terms of the number of global subscribers (Bohlin, 2012; Cave, Doyle, \& Webb, 2007; Pogorel, 2007). To be accurate, in some cases, there was no competition for GSM in Europe for example where CEPT targeted from the beginning creating common European mobile system and created a new committee which was given the name GSM (A commentary on standardization practices: lessons from the NMT and GSM mobile telephone standards historie Thomas Haug). Of course, this was not the case in the US where the government encourages neutrality among the $2 \mathrm{G}$ operators (During this time, the FCC continued its historical approach to licensing by letting the market place decide what technology to implement into any particular licensed band.--Chapter 6: GSM Goes to North America Don Zelmer1)

During the $3 \mathrm{G}$ era, the most prominent example of competition was between WCDMA and CDMA2000 1xEV-DO/DV, with the former achieving a greater number of subscribers (Hazlett, 2001). The race for $4 \mathrm{G}$ has been between the IEEE and 3GPP, which supports WiMAX and the LTE-Advanced respectively. This has ended with the later dominating the market as the single standard for 4G (Curwen, 2004; Saugstrup \& Henten, 2006).

The concept of technology neutrality has emerged with the development of personal mobile telecommunication. Initially, in Europe, for example, the European Commission (EC) enforced the exclusive use of the $900 \mathrm{MHz}$ and $1800 \mathrm{MHz}$ bands for GSM (Saugstrup \& Henten, 2006). In the 3G era, El-Moghazi, Whalley \& Irvine (2015) suggest that the influence of the policy makers in the technology development has decreased with the liberalization of the telecommunication markets. In particular, 
the calls for technology neutrality that started in the 1990s when the US government stated that there should be no assumed or required specific technologies, and that rules should be technology neutral (Curwen, 2004). Similarly, in Europe, technology neutrality has been one of the guiding principles of telecommunications regulation (Saugstrup \& Henten, 2006). Today technology neutrality is a widely recognized and accepted concept (Ali, 2009).

The practice of technology neutrality varies around the world. In Europe, GSM was mandatory for operators until 2009 (Lovells, 2014) when the use of spectrum bands reserved for $2 \mathrm{G}$ technologies were opened up to $3 \mathrm{G}$ technologies (Ali, 2009; Bohlin, 2012; Frullone, 2007; Kamecke \& Korber, 2006; Sims, 2005). Japan took the position that the $2.5 \mathrm{GHz}$ band would be reserved for non IMT-2000 technologies (Cowhey, Aronson, \& Richards, 2008), while in China the government assigned each of the three operators a particular standard, namely, TD-SCDMA, CDMA 2000 and WCDMA (Bohlin, 2012).

\section{International Mobile Telecommunication (IMT)}

In general, the ITU has been involved in the compatibility of telecommunications standards since its initial days handling the Marconi monopoly (Sims, 2006). The Marconi company refused to relay messages it received from competing operators (Newlands, 2009; Xia, 2011). Accordingly, an international conference was held in Berlin in 1903 to address the issue and to enable international interconnection (Savage, 1989). The final protocol of the conference established that wireless stations should operate in a way as not to interfere with other stations (Anker \& Lemstra, 2011). Later on, the ITU-R failed to agree on one standard for coloured TV in the 1960s with the result that three were approved. (Codding, 1991) has argued that multiple standards have been viewed by the ITU as the policy of last resort.

In general, Stepehen Blust, Chairman of ITU-R Working Party 5D, presents an excellent overview, called the SMaRT view, on the main elements of IMTAdvanced project that could be applied to IMT in general (REF: Development of IMT-Advanced: The SMaRT approach). SMaRT is an acronym for Spectrum, Marketplace, Regulatory, and Technology.

With respect to spectrum aspects, the ITU-R is involved in calculating the spectrum requirements for IMT systems and estimated spectrum bandwidth. The second element focus on establishing the overall objectives of the future development of IMT systems, and the framework for services delivered by IMT in addition to the mobile telecommunication market forecast. The regulatory aspect addresses the frequency arrangements for implementation of the terrestrial component of IMT and naming for IMT. The fourth element, technology, set the principles for development of IMT, and radio aspects for the terrestrial component of IMT. It also determined the requirements, evaluation criteria, and submission templates for the development of IMT in addition to the guidelines for evaluation of radio interface technologies for IMT- Advanced.

In the next two sub-sections, we shall focuses on two aspects namely, IMT standardisation and IMT spectrum identification.

IMT Standardisation Process

The involvement of the ITU in the standardisation process was mainly in response to the emergence of several national and regional standards bodies that were 
perceived as a threat to the role of the ITU in setting international telecommunications standards (Savage, 1989).

In particular, the lack of interoperability between 2G mobile standards motivated the ITU-R to become more involved in the standardisation process of mobile systems (ITU-R, 2007b). It was also clear that the mobile market had become large and worldwide rather than national or regional in geographical scope (Besen \& Farrell, 1991), which called for a global effort towards achieving a worldwide $3 \mathrm{G}$ standard.

The first step in the ITU standardisation activities on mobile technologies was in the 1980s when FPLMTS (Future Public Land Mobile Telecommunication System) was discussed in the ITU-R (formerly the International Radio Consultative Committee (CCIR)). That was mainly due to the support of European countries that were seeking a successor to GSM (ITU, 1998). More specifically, ITU-R Task Group 8/1 was formed in 1985 to define a framework for FPLMTS services (Funk, 1998). FPLMTS was renamed IMT-2000 by the Radiocommunication Assembly (RA) prior to the WARC-97 (U.S. Congress Office of Technology Assessment, 1993). WARC-92 also adopted resolution 212, providing the general framework for IMT-2000 standards development and system implementation (Callendar, 1994).

The ITU-R established a procedure for submitting and evaluating the IMT2000 radio interfaces proposed by the national/regional standardisation bodies (ITU, 1997). Following this, the ITU-R invited applicants for IMT-2000 radio transmission technologies in 1997 and 10 terrestrial proposals were submitted in 1998 (Leite, Engelman, Kodama, Mennenga, \& Towaij, 1997). Among these proposals, five radio interfaces were approved to be part of the IMT-2000 standards: WCDMA (also known as UMTS), CDMA 2000, TD-SCDMA, EDGE, and DECT (ITU-R, 2010). The main key requirements of IMT-2000 were set to provide data rates up to $2 \mathrm{Mbit} / \mathrm{s}$ (Engelman, 1998). In 2006 the IEEE submitted a proposal to include the WiMAX standard IP-OFDMA into the IMT-2000 family of standards (ITU-R, 2009). The ITUR RA-07 agreed in October 2007 to officially include WiMAX to the IMT-2000 family (ITU-R, 1997).

With respect to $4 \mathrm{G}$ standards, the ITU-R announced that its invitation for the submission of proposals for candidate radio interface technologies for the terrestrial components of IMT-Advanced that were agreed on in 2008 (WIMAX Forum, 2007). The main key feature of IMT-Advanced was set to be the provision of enhanced peak data rates of up to $100 \mathrm{Mbit} / \mathrm{s}$ for high mobility and $1 \mathrm{Gbit} / \mathrm{s}$ for low mobility (Sims, 2007). There were six different proposals containing two main technologies: IEEE (IEEE $802.16 \mathrm{~m}$ ) and 3rd Generation Partnership Project (3GPP) (LTE Release 10) (ITU, 2008). Later, these six proposals were consolidated into the two IMT-Advanced technologies: LTE-Advanced and WirelessMAN-Advanced (ITU-R, 2007a). These two technology standards were submitted to the RA-12 and were agreed by ITU-R member states (WP 5D Chairman, 2009). The LTE-Advanced standard was identified as LTE Release 10 and beyond, while the WirelessMAN-Advanced standard was identified as IEEE $802.16 \mathrm{~m}$ (ITU, 2010a).

Regarding $5 \mathrm{G}$ standards, the ITU-R has developed the framework and overall objectives of the future development of IMT for 2020 and beyond (ITU, 2012). One key step was for the ITU-R in 2016 to prepare the new circular letter for IMT-2020 technology applicants (ITU-R, 2012b). In February 2017, the ITU agreed on key 5G performance requirements for IMT-2020 (ITU, 2017b). One of the key characteristics of these requirements is related to the peak data rate, which were determined to be 20 $\mathrm{Gbit} / \mathrm{s}$ for downlink peak data rate and $10 \mathrm{Gbit} / \mathrm{s}$ for the uplink peak data rate. Another 
important characteristic is that for the latter user experienced data rates are $100 \mathrm{Mbit} / \mathrm{s}$ and $50 \mathrm{Mbit} / \mathrm{s}$ for downlink and uplink respectively (ITU-R Working Party 5D, 2017). The work on IMT-2020 is expected to be finalised in 2020 with the publishing of the specifications for the new IMT-2020 radio interfaces (ITU, 2017a).

While this paper sheds the lights on the ITU-R role for the IMT-2000 and IMTAdvanced technologies, the case may not be the same for the IMT-2020 era. More specifically, as the IMT-2020 standardisation is still in process and is expected to be finalised by 2020, it was not possible to collect recent information on the issue. In addition, the situation is different for IMT-2020 in terms of the competing technologies. As the IMT-2000 era has witnessed the contest mainly between CDMA 2000 and WCDMA, and the IMT-Advanced era was remarkable with the war between WiMAX and LTE, it seems that IMT-2020 will be the time of one dominant technology, namely NR by 3GPP proponent. Therefore, the issue of technology neutrality should be treated differently as neutrality would be in this case between the different frequency arrangements of NR.

Table 1 (below) displays a timeline of the ITU-R activities regarding IMT standardisation.

\begin{tabular}{|l|l|}
\hline Year & Standardisation activity \\
\hline 1985 & $\begin{array}{l}\text { The ITU-R Task Group 8/1 was formed to define a framework for FPLMTS } \\
\text { services }\end{array}$ \\
\hline 1997 & The name FPLMTS was renamed IMT-2000 \\
\hline 1997 & The ITU-R invited applicants for IMT-2000 \\
\hline 1998 & Ten terrestrial proposals were submitted for IMT-2000 \\
\hline 1999 & Five radio interfaces were approved to be part of the IMT-2000 standards \\
\hline 2006 & The IEEE submitted a proposal to include WiMAX into the IMT-2000 \\
\hline 2007 & RA-07 agreed to include WiMAX to the IMT-2000 family \\
\hline 2008 & $\begin{array}{l}\text { The ITU-R announced its invitation for the submission of applicants for IMT- } \\
\text { Advanced }\end{array}$ \\
\hline 2009 & $\begin{array}{l}\text { Six different proposals containing two main technologies (IEEE (IEEE } \\
802.16 m \text { and LTE Release 10) were submitted }\end{array}$ \\
\hline 2012 & The RA-12 approved the two technologies to be part of the IMT-Advanced \\
\hline 2016 & Start of IMT-2020 Circular letter preparation \\
\hline 2020 & Finalisation of IMT-2020 technologies specifications \\
\hline
\end{tabular}

Table 1: Timeline of the ITU-R Activities on IMT Standardisation

\section{IMT Spectrum Identification}

The IMT standardisation process has been associated with identifying the radio spectrum bands to be used by these IMT standards (e.g. $2 \mathrm{GHz}$ band). The first step with this regard was when the European countries called for spectrum allocation for FPLMTS in the mobile WARC of 1987 but the issue was postponed until WARC92. During WARC-92, countries such as the United States opposed allocating new frequencies for FPLMTS (Osseiran, 2013). Eventually, the conference identified the bands $1885-2025 \mathrm{MHz}$ and $2110-2200 \mathrm{MHz}$ for countries wishing to implement FPLMTS (ITU-R, 2016). Table 2 (below) shows a timeline of the IMT spectrum identification by different WRCs. 


\begin{tabular}{|c|c|}
\hline WRC & IMT Identified bands \\
\hline WARC-1992 & $1885-2025 \mathrm{MHz}$ and $2110-2200 \mathrm{MHz}$ \\
\hline WRC-2000 & $806-960 \mathrm{MHz}, 1710-1850 \mathrm{MHz}, 2500-2690 \mathrm{MHz}$ \\
\hline WRC-2007 & 450-470 MHz, 698-806/862 MHz, 2.3-2.4 GHz, and 3.4-3.6 GHz \\
\hline WRC-2012 & $694-790 \mathrm{MHz}$ \\
\hline WRC-2015 & $\begin{array}{c}\text { 470-694 MHz, } 1427-1518 \mathrm{MHz}, 3300-3400 \mathrm{MHz}, 3400-3600 \mathrm{MHz}, 3600- \\
3700 \mathrm{MHz}, 4800-4990 \mathrm{MHz}^{1}\end{array}$ \\
\hline
\end{tabular}

Table 2: Timeline of IMT Spectrum Identification (ITU-R, 2001a, 2008, 2012a,

2015a; U.S. Congress Office of Technology Assessment, 1993)

In this section, we have focused on two main activities related to IMT technologies, namely, IMT standardisation and IMT spectrum identification. While the former has evolved from IMT-2000 to IMT-Advanced and then to IMT-2020 under the label of IMT, the later has expanded over the years through different WRCs. The next section outlines the methodology adopted in order to explore how IMT and national radio spectrum management policies interact with regards to technology neutrality.

\section{Methodology}

This section explains the research methodology adopted in order to examine the interaction between IMT and national spectrum decision regarding technology selection and neutrality. A qualitative methodology is adopted that utilises an inductive approach where the theory is developed upon the observations or the findings of the research (ITU-R, 2012c). The paper draws on primary data collected from 55 semi-structured interviews with interviewees from national regulators, mobile industry, ITU-R study groups and working parties.

In particular, this includes the main stakeholders from the different ITU-R three regions and covers 21 countries (including Brazil, Canada, Egypt, Finland, France, Germany, India, Ireland, Japan, Kenya, USA and the UK). The 52 interviewees cover 10 operators, 11 equipment manufacturers, 7 consultants, and 24 telecommunications regulators who participate in the activities of the ITU-R Working Party 5D, which is concerned with IMT issues. These are the interviewees that the researcher managed to get their agreement. Only one interviewee from international operators refused to conduct the interview. In general, all interviewees were cooperative and answered all questions.

The following table shows in details the title, group, and role of each of the interviewees.

\begin{tabular}{|c|c|c|}
\hline Title & Group & Role \\
\hline Spectrum Management Head & Regulator & Involved \\
\hline Senior Manager Spectrum. & Regulator & Observer \\
\hline Manager Spectrum Policy & Regulator & Involved \\
\hline Engineer Spectrum Allocation & Regulator & Involved \\
\hline Permanent Representative in ITU & Regulator & Involved \\
\hline
\end{tabular}

${ }^{1}$ Some bands were identified in few countries. 


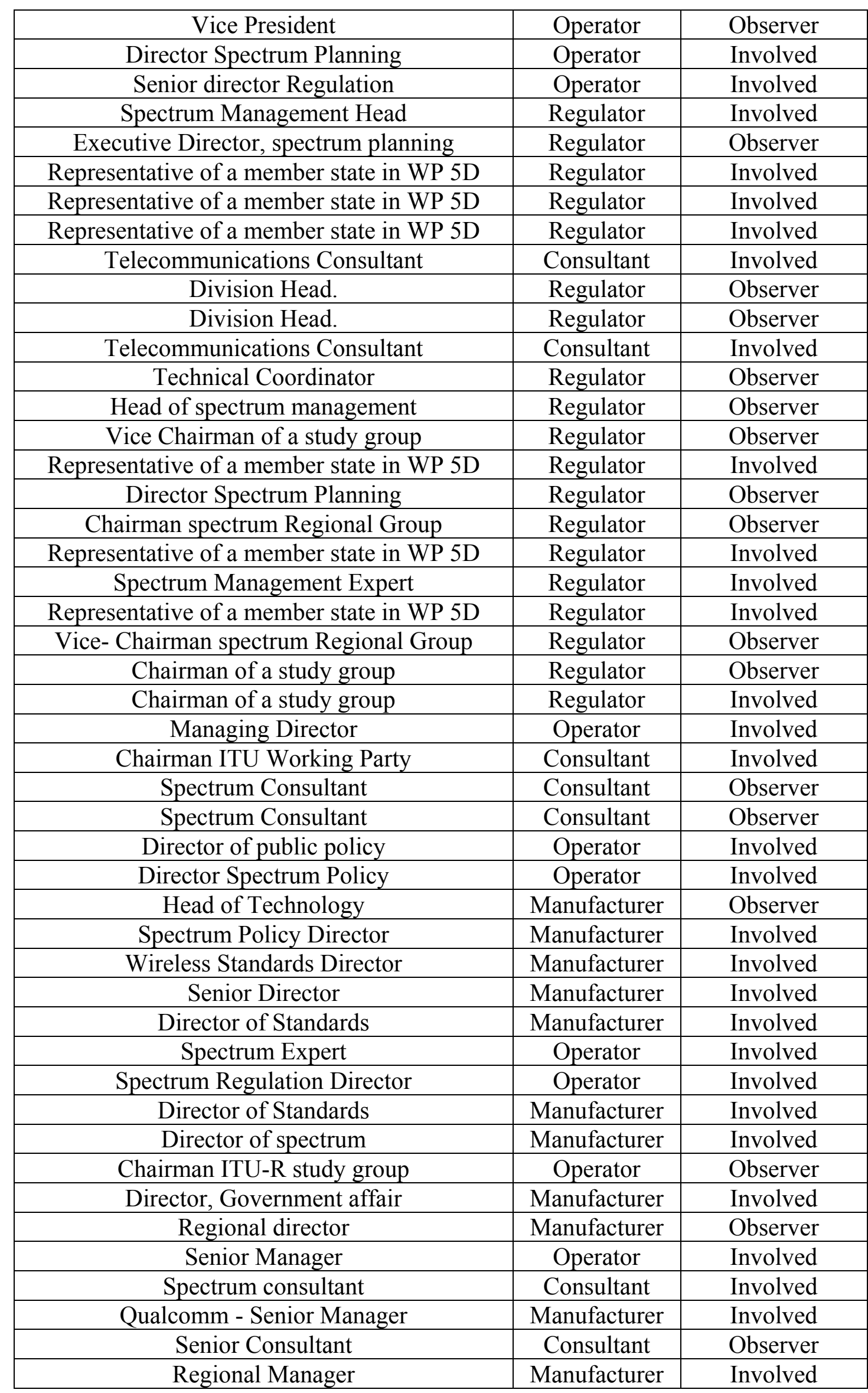

Table 3: Categorisation of Interviewees 
It should be noted the paper does not intend to identify the identity of the interviewees for each answers, as that would involve revealing their formal opinion on the different aspects of the IMT process, which was not possible for most of them. However, in order to overcome such deficiency, Table 3 identifies the background of each interviewee and whether he/she is part of the IMT process per se or just observing the process while not attending the ITU-R WP 5D meetings.

The core questions asked to each of the interviewees were as follows:

1. Is being part of the ITU IMT-2000 and IMT-Advanced technologies mandatory for introducing a technology for cellular mobile?

2. Do you define $3 \mathrm{G}$ and $4 \mathrm{G}$ services according to the ITU-R IMT-2000 and IMT-Advanced standards?

3. What are the pros and cons of having spectrum identified for IMT?

The same questions were, in essence, asked to each of the interviewees with different wording according to the context and to background of the interviewee (that is, whether they were from a regulatory agency, telecommunications operator etc.). Some additional questions were, however, asked to specific participants such as, for example, those who supported WiMAX. In addition, some other questions were asked to stimulate the discussion at the beginning of the interview and to understand the background of the interviewees. For instance, some interviewees were asked about their definition of technology neutrality and their opinion on such concept (benefits threats). Also, regulators and operators were asked whether it is allowed to re-farm their spectrum for other technologies (e.g. LTE in $900 \mathrm{MHz}$ ). In general, the period of the interviews were conducted in the time before the work on IMT-2020 between the year 2012 and 2014. Accordingly, it was not possible to include the 5G discussions in the paper.

One remark to be mentioned is with respect to the research philosophy of the paper. In general, research philosophy impacts the researcher's view of the relationship between knowledge and the process by which it is developed. Having said that, this research adopts the interpretivism paradigm as the philosophical position for this research for several reasons. Firstly, this research embraces the subjective ontological position which holds that social phenomena are created from the perceptions and consequent actions of social actors (Saunders et al., 2009). More specifically, it is argued that the regulatory aspects of spectrum management are socially constructed by the policymakers' views and beliefs where these views are not constant and may change according to the complex and relatively unique circumstances of each country. These views vary across the different stakeholders' position. Additionally, this research does not target generalisation but rather to examine closely specific context in order to answer the research questions.

Subsequent to the interviews data reduction occurred. This is the process of selecting and simplifying the data from the interviews (ITU-R, 2015c). Data reduction has been achieved in this paper through coding, a process that breaks data down into component parts that are named (Bryman \& Bell, 2007). Coding is used to link data to ideas and also to identify links between the different ideas (Miles \& Huberman, 1994). NVivo was used for this purpose, facilitating the identification of the most important themes (Bryman \& Bell, 2007).

In order to verify the coding, three independent coders that possessed good knowledge of spectrum management and the ITU-R were selected to double code 
selected interviews to ascertain the veracity of the approach adopted in this research. A protocol was designed for the coding verification process that included systematic steps to enable the coders to verify the coding. A meeting was held with the coders after the verification process to discuss their comments.

It should be noted that the selected interviews for double coding were chosen for having the largest number of associated 'nodes' where each concept (e.g. technology neutrality) is associated with a node (Bazeley, 2007). More specifically, a node is defined as a collection of references about a specific theme and coding with Nvivo is defined as the process of marking passages of text in a document with nodes (Miles \& Huberman, 1994).

The third step was data display in order to present the information systematically to shape the drawing of conclusions (Bazeley, 2007). Data was displayed after its reduction for a variety of reasons (Bryman \& Bell, 2007). Firstly, it is difficult to analyse spread and scattered data. Secondly, the process of drawing conclusions for the readers from data display is more comprehensive than from the extended text. Moreover, data display helps discover new relationship and propose explanations.

In this paper we display data by concepts. While there are several formats for such type of network display, this paper adopts the graphical representation of 'cognitive mapping' that is a causal based mapping technique that is used mainly to represent the subjective world of interviewees (Miles \& Huberman, 1994). More specifically, a cognitive map is a graphic tool that is used to represent concepts and ideas that individual associates with some specific issue (Miles \& Huberman, 1994). A causal map is defined as a cognitive map that incorporates concepts linked together through causal relationships (Eden, 2004). In causal maps, nodes represent concepts and arcs demonstrate directional relationship between these nodes (Albino, 2003). Cognitive mapping is used mainly to represent the subjective world of interviewees (Prigenta, Fontenellea, Rochetb, \& Trenkelb, 2008), and it is based on the Kelly's personal construct theory (Kelly, 1955; Topcu, 2014) as it presents person's construct system which they are able to and willing to make explicit (Eden and Ackermann, 1998b). Kelly (1955) proposed that in order to understand how individuals organise their environment, the individuals themselves should define the relevant dimensions of that environment (Eden, 2004).

Decision Explorer was chosen to display the data because it was designed specifically to support cognitive mapping (Eden \& Ackermann, 1998). The software facilitates the handling of complexity in the 'maps' of related concepts. One feature that was useful is the ability to have a style for each concept or user defined links. For reasons of simplicity, the researcher adapted three types of styles for displaying concepts as shown in Figure 1 (below). 


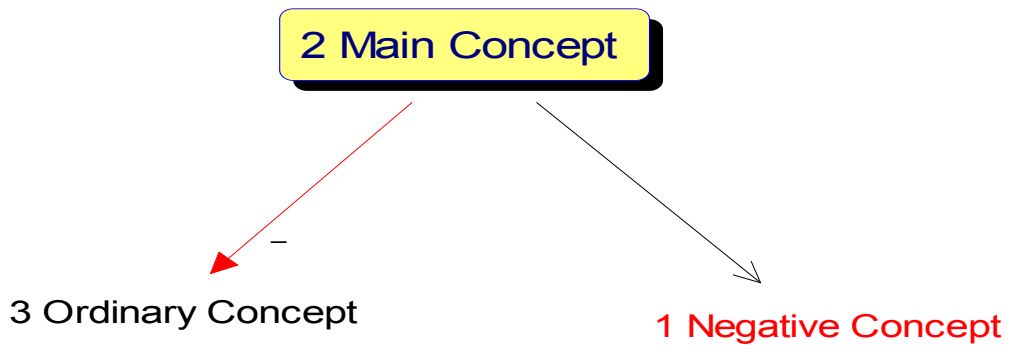

Figure 1: Link and concept Styles

Concept 1 , in red font, is negative, as interviewees perceive such a concept adversely or unfavourably. Concept 2 , in yellow box and blue font, is a main or key concept that was identified during the data analysis, while Concept 3 , in black font, is a typical or normal concept. The black arrow represents a causal link whereas the red arrow implies negative relationship or link (that is, decreases, negatively influence). These different styles are the keys of the maps to be used later on.

One downside of Decision Explorer is that it creates an automatic numbering system that does not convey any specific meaning. These numbers are in the order of creating these concepts in the program database.

In order to verify the data display process, four independent researchers were selected to map selected topics. The next four sections shall address the paper's four questions based on the primary data collected from the interviewees that are all involved in the IMT activities at the ITU-R.

\section{Influence of IMT Standardisation on Technology Selection and Technology Neutrality}

This section addresses the first of the four research questions noted above in Section 2. The data analysis of the interviews revealed two views regarding the IMT standardisation influence on technology selection considering the views of thirty-three interviewees. There is a view shared by twenty-one interviewees that being part of the IMT family has a positive influence on the regulators' decision regarding technology selection. This is due to several reasons. Firstly, IMT could be considered as an encouragement for countries to adopt internationally accepted standards. It is also argued that it is in the interest of a country to comply with IMT standards in order not to lose the benefits of economies of scales and roaming. In addition, IMT technologies are recommended by the ITU-R. This provides them with a certain degree of authority that encourages their adoption.

Besides, being part of IMT is necessary to define sharing conditions with neighbouring services and indicates that the used equipment will be consistent with frequency bands and will offer backward compatibility with previous generations of equipment. Also, developing countries, which lack technical resource to judge technologies, rely heavily on the ITU-R recommendations. In these countries, it is 
important for manufacturers to get their technologies listed in the IMT so that their technology could be used globally.

The second view, shared by 12 interviewees, was that being part of the IMT technologies is not related to the decisions of regulators regarding technology selection for several reasons. As expressed by one interviewee from a mobile operator "I do not restrict myself with the ITU, because it serves me. The ITU is the one who serves". Firstly, first priority for any technology is to be worldwide one with low cost handsets more than being standardised by the ITU. For instance, one senior interviewee from the mobile industry in Africa mentioned that regulators in Africa did not know if CDMA-2000 is one of the IMT-2000 family or not but it was the vacant spectrum that attracted the vendors to deploy the technology in Africa. Having a technology out of the IMT family (for example, IBurst) depends on whether the technology is capable of solving a problem in a particular country. One senior interviewee from CEPT argued that the influence from CEPT and European Commission (EC) is more important than the influence of IMT in Europe. The different views regarding the influence of IMT on technology selection are displayed in Figure 2.

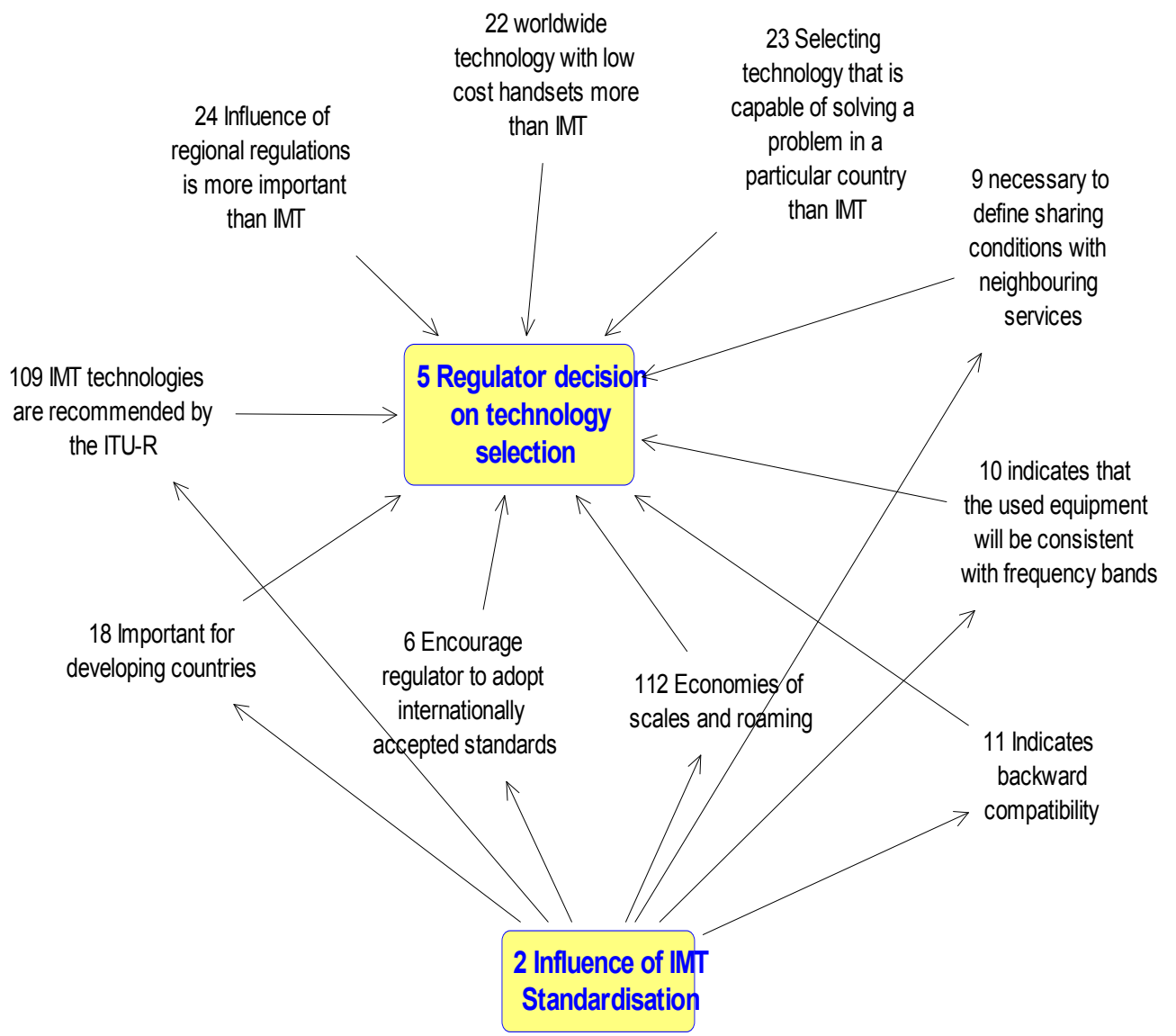

Figure 2: Influence of IMT Standardisation on Regulator's Decision on Technology Selection 
Figure 2 reveals two different views on the importance of being part of the IMT technologies that regulators include in their deliberations. One view is that such influence is significant for a variety of reasons (concepts 18, 6, 112, 10, 9, 11, 109). On the other hand, there was a view that being a IMT technology is of secondary importance to other factors that have a greater influence on the regulator's decisions on technology (concepts 24, 22, 23).

With respect to the influence of IMT standardisation process on national regulators regarding technology neutrality, the interviews revealed three views from 25 interviewees. Firstly, 11 interviewees shared the view that the IMT process has positively influenced the approach of regulators towards neutrality for a variety of reasons. The standardisation process in ITU-R has helped the regulator to move forward to more technology neutral approach. In particular, IMT encourages regulators to have licenses that allow any IMT technology or any technology that complies with the emission mask of IMT. For instance, it has encouraged the European countries to be more neutral especially at the time when they were limited to ETSI technologies and companies like Qualcomm wanted to include CDMA 2000 in $3 \mathrm{G}$ in Europe.

Furthermore, it was argued that IMT encourages regulators to have licenses that allow any technology that complies with the emission mask of IMT. IMT also gives regulators the possibility to a greater extent to introduce more technology neutrality regulation because there is a family of technologies that can be used. Although there are certain requirements and conditions for a technology to be part of the IMT family, this is not considered to be a constraint. This is because access to being part of the family of IMT standards is open provided the minimum technical conditions can be met by the applicant technology. Furthermore, all technologies applied for IMT-Advanced were approved and if a new technology appears, they could be included on the condition they meet the requirements of IMT. As expressed by one of the interviewees: "let's not speak of IMT technologies; it's wrong. IMT is like a system objective. Any technologies which met the minimum objectives are welcomed".

Moreover, while it is not mandatory for an IMT technology to be adopted, almost all technologies are part of the IMT family. Therefore, even if a regulator is technology neutral, most probably the adopted technology would be IMT. One other interviewee argued that the intention of the ITU-R is not to make any IMT mandatory. As explained by him "it is because the ITU does not want to impose too many things on its membership... ITU standards are actually a catalogue of possible solutions but none of them is imposed". In particular, countries are sovereign and there is nothing that forces them to adopt IMT standards. Therefore, it is up to national regulators to reference or just acknowledge IMT.

Furthermore, some of the interviewees considered that the IMT process is open and transparent, as it involves independent assessment groups. Therefore, there was no a priori judgement against any specific technology. This was supported by another interviewee who argued that the IMT process is itself technology neutral because the process has defined quality and performance. Accordingly, the different technologies, which can meet these objectives of performance, are called IMT. In addition, even within technology neutrality, technical conditions are designed with some assumptions about the technology, which could be IMT. 
Regarding non-IMT technologies such as IBurst, it was pointed out that the ITU has not stopped IBurst from operating because there was a different model for IBurst that is based on operating in particular guard bands. Instead, IBurst was not successful due to the advancement of LTE and lack of handsets rather than because it was not part of the IMT family.

On the other hand, one contrasting view shared by seven interviewees that specifying technologies to be only IMT is restrictive and not as neutral as it looks. As expressed in this quote "you realize you are doing subsection of technology neutrality". Firstly, having a defined family of standards such as IMT discourages regulators from being neutral as it would be easier to limit access to the spectrum to the IMT family of standards. This is one of the reasons why WiMAX fought to be a IMT standard. Secondly, it limits the ability of operators to move to a more efficient technology when it becomes available. Thirdly, it was perceived that in cases where countries issue licenses for IMT, at the end of the day, operators will use LTE.

Moreover, one interviewee argued the IMT is used to keep competitive technologies off the list of possible technologies. One other view was that introducing new radio interfaces into the IMT family is quite difficult and requires a lot of time and money. Furthermore, although neutrality and IMT standards may be independent, the concept of IMT harmonisation is more or less against technology neutrality.

The IMT process may restrict innovation in new technologies. In particular, companies supporting the $4 \mathrm{G}$ technologies want to postpone the discussion on $5 \mathrm{G}$. As expressed by one interviewee:

from a bipolar world of '90 you move to unipolar world, and the unipolar world is IMT and because of that the innovation has taking a little back seat...governments in the world is focused on how do we make use of this technology, how do we make it more useful to us, rather than thinking what's next.

In other words, while there was competition in the early days of personal mobile communication, between GSM and CDMA, today LTE is the dominant technology. This has resulted in moving the focus away from the development of the next technological generation to the utilisation of the current generation.

The third view, expressed by seven interviewees, is that both the issues of IMT standardisation and applying technology neutrality are independent, and that the influence of IMT is more on the manufacturers rather than the regulators. In particular, some countries adopt technology neutrality before the beginning of the IMT standardisation activities. Instead, it is the technology development that drives the neutrality issue due to the need to deploy other advanced technologies in the same spectrum band without getting a new license every time. In support of this, one interviewee stated "technology neutrality is really something which is for the regulator. This is not something that the ITU cannot mandate or orient it in any way". All the different views regarding the influence of IMT on technology neutrality are displayed in Figure 3. 


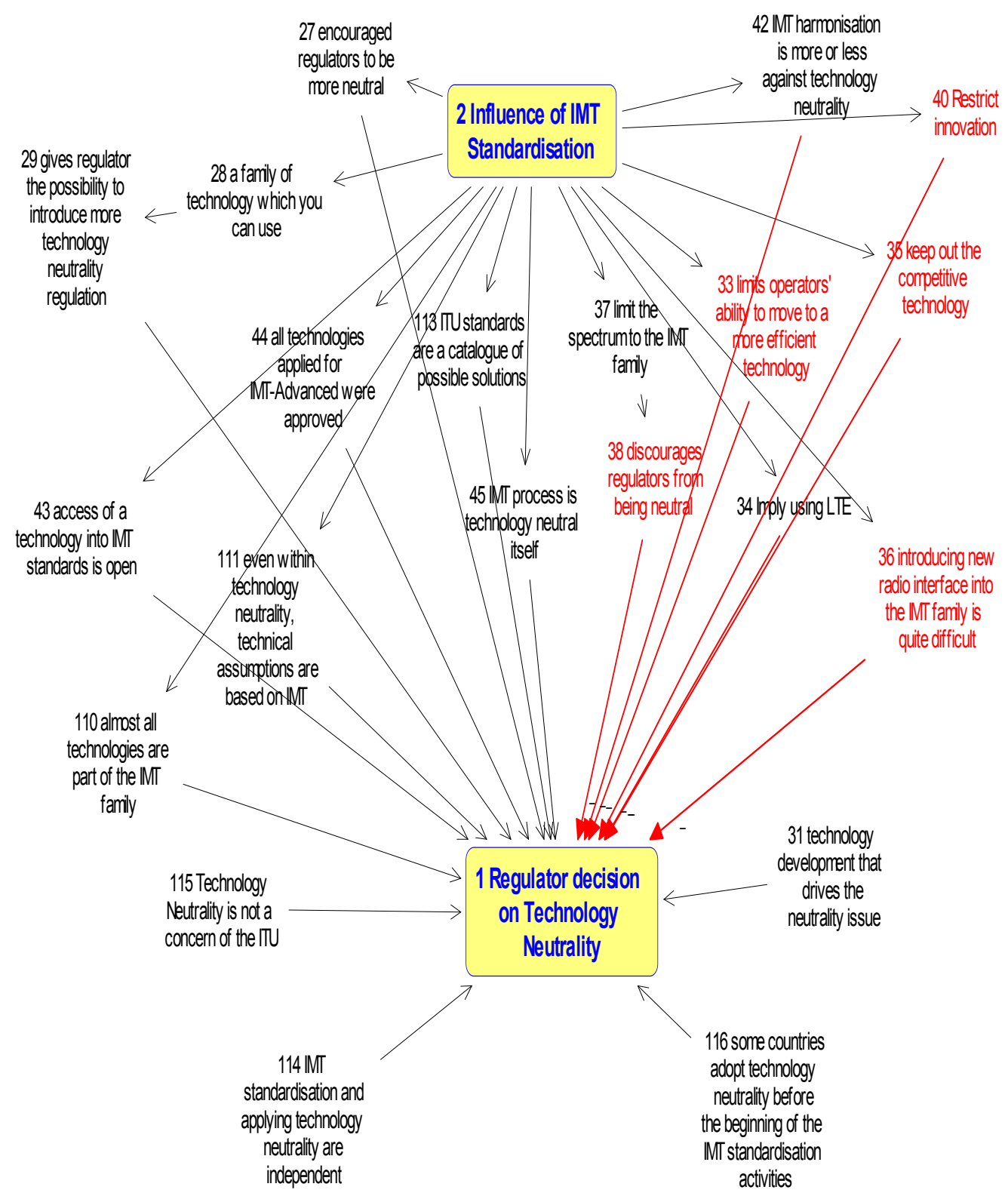

Figure 3: Influence of IMT Standardisation on Regulator's Decision on Technology Neutrality

Regarding the influence of IMT standardisation on technology neutrality, Figure 3 shows the complexity of the issue. In particular, there are elements that encourage more neutrality approach in technology selection (concepts $28,29,27$ ), and elements that support the argument that the IMT family of standards is considered to be in conformity with technology neutrality (concepts 43, 110, 44, 111, 113, 45).

The map also highlights the contrasting view that IMT standardisation is against the concept of technology neutrality and may discourage regulators form being neutral for several possible reasons (concepts 37, 38, 34, 42). Most importantly, 
the radio spectrum, which is a critical asset in providing wireless services, is set aside for IMT technologies as it is harmonised internationally for IMT. The map shows that the IMT standardisation process may have negative influence on operators (concept 33) and technology developers (concepts 35, 40, 36). Moreover, there is an argument that IMT standardisation does not have influence on adoption of technology neutrality (concepts 31, 114, 115, 116).

These findings highlight that being part of the IMT family of standards provides support to the applicant technologies. However, there are other elements that may have stronger influence on decisions regarding adopting a particular technology rather than being IMT technology. Moreover, IMT standardisation has positive (supportive), negative (opposing), and neutral elements in terms of the influence on regulators regarding technology neutrality according to the perception on technology neutrality and on the IMT standardisation process per se.

\section{Influence of IMT Standardisation on Perspectives regarding Mobile Technology Generations Definition}

This section addresses the second of the research questions, namely, what is the influence of the IMT standardisation process on the perception of mobile technology generation definition. More specifically, it is important to examine whether the ITU-R definitions of IMT-2000 and IMT-advanced technologies have an influence on the perception and differentiation between $3 \mathrm{G}$ and $4 \mathrm{G}$ services.

In general, two distinct views emerged from the interviews on the influence of IMT on mobile technology generation definitions $(3 \mathrm{G}, 4 \mathrm{G})$ by 27 interviewees. The first view shared by 22 interviewees is that there is no influence. It was explained that $3 \mathrm{G}$ and $4 \mathrm{G}$ are marketing terms that have nothing to do with the ITU. The ITU has been reluctant to use these marketing terms $(3 \mathrm{G}, 4 \mathrm{G})$ because of how the technology evolves (for example, 3.75, 3.9) rather than revolutionary change (IMT-2000, IMTAdvanced). Moreover, there was a decision in the WP 5D not to use the terms of $3 \mathrm{G}$ and 4G. As expressed in this quote "the ITU would not be called caught in a situation of giving a false expression impression".

It was also expressed that the IMT umbrella provides a high level of definition and that the ITU-R sets vision without much detail. One interviewee who is involved in the activities of the WP 5D argued that the influence of the IMT was much less in the case of $4 \mathrm{G}$ than the $3 \mathrm{G}$ as certain regulators were not concerned with the term IMT-Advanced. Moreover, the industry parties did not care much about what the ITU-R was doing in the case of IMT-Advanced. This interviewee's remark supports this:

"there were those in the marketplace who felt that their position in the marketplaces as operators or others was enhanced by waving a flag saying, We are 4G, therefore we do not care to have $4 G$ defined, because if it is defined, it's probably not going to be what we are doing".

On the other hand, the second view is that influence does exist between IMT standardisation and the definition of technology generations. It was argued that the commercial and IMT definitions go hand-in-hand and that the ITU-R definitions were 
strongly influenced by the industry representatives at the WP5D meetings. Interviewees argued that there was influence in the case of $3 \mathrm{G}$ because it was an emerging green field market as the ITU-R recommendation M.1457 stated clearly that these are the $3 \mathrm{G}$ technologies, thus drawing a clear distinction between $2 \mathrm{G}$ and $3 \mathrm{G}$.

One issue that was raised during the interviews is the influence of IMT standardisation on the definition of $4 \mathrm{G}$. Interviewees have revealed the view that LTE is and its evolution from are branded as IMT-2000 according to the ITU-R recommendation ITU-R M.1457, while LTE-Advanced is categorised as IMTAdvanced according to the recommendation ITU-R M.2012. Therefore, only LTEAdvanced is considered as $4 \mathrm{G}$.

The other view shared by five interviewees is that for regulators, LTE is $4 \mathrm{G}$ even if the ITU-R does not categorise it as IMT-Advanced. As clarified by one of the interviewees "if $4 G$ is IMT-Advanced, nobody has it". One interviewee who is involved in the WP 5D activities argued that there is no real strict definition of 4G. $\mathrm{He}$ highlighted an example in the US where T-Mobile came out and stated that "we do not have any LTE, we do not have any IMT-Advanced, we do not have any of this and that. But what we've got is $4 G$, because it's fast". The influence on commercial definition varies from country to another. For instance, in Japan, LTE is understood to be $3 \mathrm{G}$. On the other hand, T-Mobile in the US branded their HSPA+ as 4G technology while Verizon considered LTE to be a true 4G (Goldman, 2010; Ziegler, 2011a). Meanwhile, AT\&T considered both of LTE and HSPA+ to be $4 \mathrm{G}$ technologies (Ziegler, 2011b).

It is worth noting that the ITU clarified in 2010 in a press release that while IMT-Advanced is considered as $4 \mathrm{G}$, the term ' $4 \mathrm{G}$ ' per se may also be applied to the forerunners of these technologies - that is, LTE and WiMAX - and to other evolved 3G technologies (ITU, 2010b). 


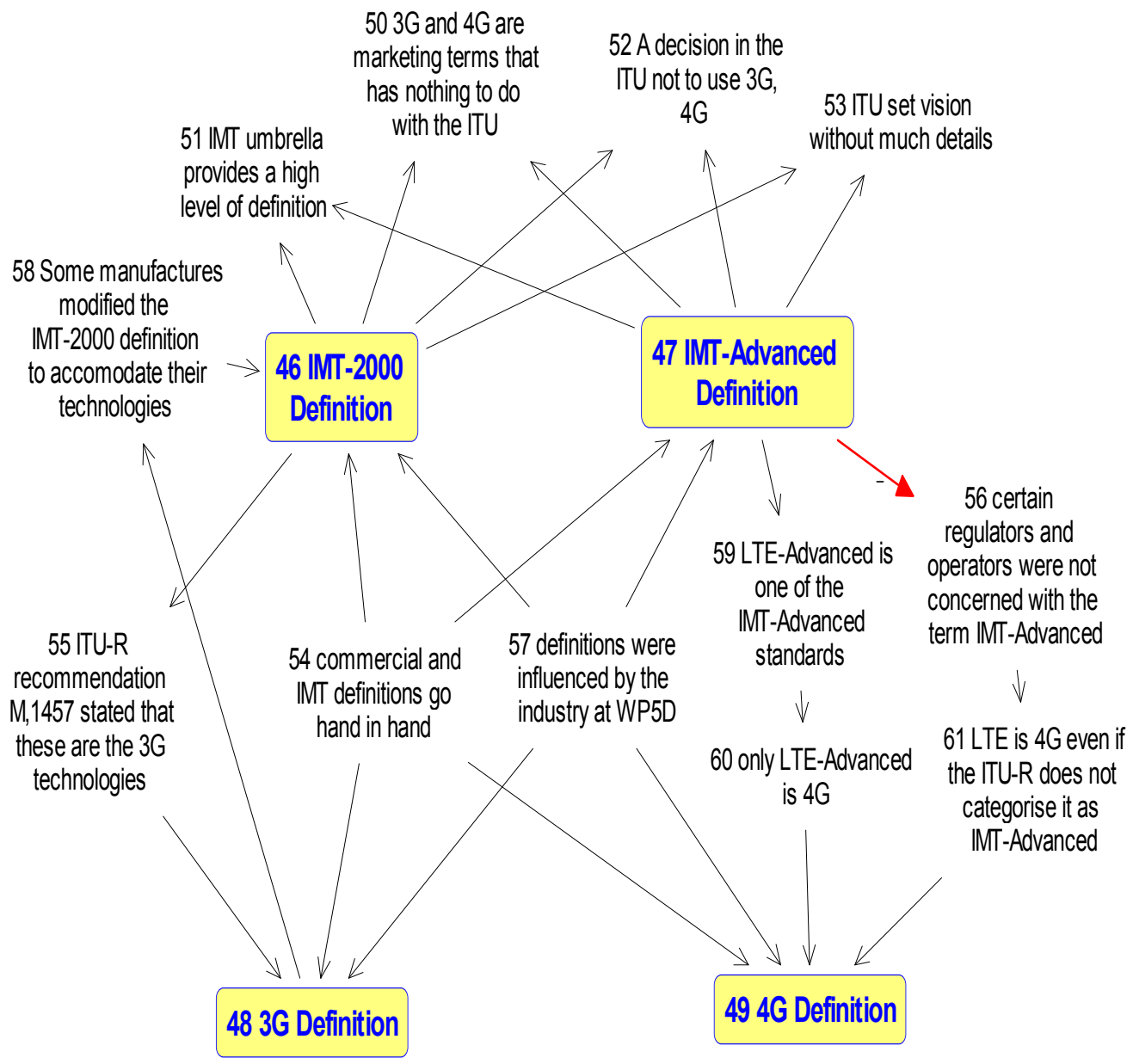

Figure 4: Influence of IMT Standardisation on Perspectives regarding Mobile Technology Generations Definition

Figure 4 reveals several observations on the interaction between the IMT standards and $3 \mathrm{G}$ and $4 \mathrm{G}$ definitions. Firstly, several actions were taken in the ITU-R to diminish any influence from the IMT standards on the technology generations terms used in the market (concepts 51, 50, 52, 53). On the other hand, there is a view that both IMT and commercial definitions are developed in parallel (concept 54) and that both definitions are influenced by the industry (concept 57). Regarding the influence from the industry on the IMT definitions, there is a view that there was an influence specifically from the market on the IMT-2000 (concept 58). Similarly, there was an influence from the IMT-2000 definitions on categorising what should be labelled as $3 \mathrm{G}$.

Regarding 4G, there are two views. The first is that only LTE-Advanced is considered to be $4 \mathrm{G}$ only because LTE-Advanced is included in the IMT-Advanced standards and not LTE. The second view is that this is not the case as LTE is still considered by many as a $4 \mathrm{G}$ technology although LTE is not one of the IMTAdvanced technologies. These observations imply that while one view is that there is 
an influence between the IMT definitions and definitions of $3 \mathrm{G}$ and $4 \mathrm{G}$, the other view is that there is no influence because the ITU-R has taken several actions not to influence the market.

\section{Influence of IMT Standardisation on Discrimination between Technology Generations}

This section addresses the third research question, that is, the influence of the IMT standardisation on the discrimination between mobile technology generations. In particular, the analysis of the interviews revealed two contrasting views held by 26 interviewees. The first view which was shared by 18 interviewees is that there is no influence on the discrimination between generations. In particular, the issue of having IMT-2000 and IMT-Advanced under one label - IMT - has provided more flexibility in spectrum use. Accordingly, most regulators have started to use IMT as a single name so that operators can move from technologies such as WCDMA to directly LTE. This was also confirmed by another interviewee who argued that the ITU-R does not mention IMT-2000 or IMT-Advanced anymore. Instead, the use of the term IMT shows that the neutrality of system in spectrum bands is already under consideration by ITU-R. However, this may not be the case for some regulators because they have licenses with specific conditions.

One interviewee clarified the origin of the decision of having IMT-2000 and IMT-Advanced under one label. It was described that the ITU-R actually banned the $3 \mathrm{G}$ and $4 \mathrm{G}$ terms and started removing them from all ITU-R documents. This is due to the original intention of IMT-2000 as $3 \mathrm{G}$ and IMT-Advanced as 4G. However, there were technology upgrades within IMT-2000 and those upgrades have been called 4G. This resulted in a degree of confusion. The reason for having one label, IMT, was to ensure that the footnotes in the RR identified spectrum for IMT could be used for all of the technologies instead of having spectrum identified separately for IMT-2000 and IMT-Advanced. Another reason for the IMT label was that IMT-2000 was expected to be deployed around the year 2000 and to be linked to the $2000 \mathrm{MHz}$ band, which eventually did not happen. Therefore, it was decided to use the term IMT.

One point that was raised is that although LTE is included in the ITU-R recommendation M.1457 and LTE-Advanced in ITU-R recommendation M.2012, LTE release 10 is also included in M.1457 (ITU-R, 2017). As expressed by one of the interviewees "they're going to keep updating on it, so they were going to have it in both places". Therefore, there would be an overlap between the two recommendations so that there would be no discrimination between IMT-2000 and IMT-Advanced. In addition, one senior interviewee clarified that one of the requirements for IMTAdvanced was to be backwardly compatible with the IMT-2000 to ensure that there is an evolution between the two of them.

A senior interviewee from the mobile industry argued that the differentiation is due to historical reasons as most of the $3 \mathrm{G}$ licenses were awarded by beauty contest. As stated by him "all the history of what we done in the past probably drive the resistance to making it completely technology neutral". More specifically, the relatively higher license fees paid in some of the $3 \mathrm{G}$ licenses made it difficult for the 
regulators to allow operators who had spectrum used for $2 \mathrm{G}$ technologies to use it for $3 \mathrm{G}$. Moreover, it was argued that the license matters are a national consideration that the ITU-R should not get involved in.

It was also mentioned that regulators differentiate between generators not only for getting higher license fees but also in terms of prestige. As expressed by one of the interviewees "I had noticed in countries in Latin America is that is a matter of prestige, when the government says ah we have the latest technology this is $4 G$ and that's spectrum they make a big fast of update". In addition, regulators usually refer to the common practise rather than the ITU-R.

On the other hand, there was a view, shared by eight interviewees, that having IMT-2000 and IMT-Advanced labels could be used as an excuse for regulators to differentiate between technologies. As expressed by one of the interviewees from WP 5D "it has an influence. But everything has an influence. It could be used that way". It was also mentioned that this is not the intention of the ITU-R. One senior interviewee, from the mobile industry, highlighted the issue of EDGE being considered as $3 \mathrm{G}$ due to it being included in the IMT-2000 family although EDGE was obviously a $2 \mathrm{G}$ standard. The interviewee further raised the point that the LTE technology may face similar situation because it is mentioned in IMT-2000 and IMTAdvanced recommendations.

Figure 5 shows that there are several reasons why regulators differentiate between technology generations due to issues related to the telecommunication market circumstances nationally (concepts 66, 73, 74, 77). Furthermore, regulators may discriminate between the different technology generations in order to obtain higher license fees (concept 76). Regarding the influence of the IMT standardisation process on such discrimination, Figure 5 illustrates that the ITU-R, through a variety of different actions, has reduced the variation between IMT-2000 and IMT-Advanced (concepts 64, 65,72) and has not being involved in discussions related to the differentiation between $3 \mathrm{G}$ and $4 \mathrm{G}$ (concept 69 ). The ITU-R does not involve itself in national matters (concept 75) and national regulators usually refer to 'common practise' rather than the ITU-R (concept 80). However, there was view that national regulators could use the IMT-2000 and IMT-Advanced labels to justify such discrimination (concept 81). These findings, therefore, show that the IMT standardisation has largely no influence on the discrimination between technology generations on the national level. 




Figure 5: Influence of IMT Standardisation on Discrimination between Mobile Technology Generations

\section{Influence of IMT Spectrum Identification on Technology Selection and Technology Neutrality}

One area that needs further focus is the IMT spectrum identification in the RR. This is because it is unusual in the RR to identify spectrum specifically for a particular technology. Instead, spectrum is allocated to radiocommunication services (for example, fixed or mobile). The interviews revealed several areas of influence of IMT spectrum identification on a regulator's technology selection decision. Firstly, it was 
perceived that the ITU is one of the most significant authorisation entities in the telecommunication world, and, therefore, many vendors and operators like to obtain the authorisation of the ITU for the used frequency bands.

Thus, the identification sends strong signals to the manufacturers of equipment that these are the bands that they should focus and concentrate on when developing their mobile technology in order to achieve harmonisation, roaming and economies of scales. It is worth noting that there are technological limitations so that it is only possible to have a handset that supports specific bands (Brodkin, 2013). The alternative would be to consider all the spectrum bands allocated to mobile service. This was supported by a senior interviewee from the mobile industry who stated that "we do not want to go down the road and develop something if it is not going to see the light at the end of the day". The identification also sends signals to the regulators to ensure that they had identified those spectrum bands that could be used for IMT at a time that is appropriate when they decided to introduce it into their countries. In addition, designation or identification was argued by several interviewees to make spectrum more valuable. As expressed in this quote "physics did not change, but the fact that you now designated IMT suddenly you raking in millions".

One other interviewee argued that such identification could raise the value of spectrum and increase the license fees that operators are willing to pay. This was confirmed by a senior interviewee from CEPT, who explained that IMT identifications through WRCs have always been followed by spectrum awarding activities. Moreover, IMT spectrum identification is important for regulators, which are not as advanced as large regulators (such as FCC) in terms of making their own decisions. For these regulators, it is difficult to conduct studies to decide on which bands would be used for IMT technologies. As a consequence, they instead rely on the ITU to take such decisions.

Another advantage that was mentioned by several interviewees is that when regulators auction spectrum bands identified for IMT technologies, there is a guarantee that you will have devices in these bands. Moreover, a senior interviewee explained that identification is an indication that most of the countries using this service in the particular band will follow the IMT standards. In addition, one interesting point that was raised by one of the interviewees is that having a particular spectrum band identified for IMT gives support to the regulator to re-farm the spectrum from its existing use. An example of that is the $700 \mathrm{MHz}$ band IMT identification, where several regulators were considering deploying mobile service in the $700 \mathrm{MHz}$. As one interviewee explained:

"they did not want to even mention it because they knew that the broadcasters in their country, TV broadcasters, will be very upset, will make a lot of fuss and it will be very difficult. But once the ITU has said this band is going to be used for mobile, it made it much easier for regulators to say, well this is not my idea but look the rest of the world think this band should be $700 \mathrm{MHz}$ ".

The interviewees mentioned several case studies that show how the influence of IMT spectrum identification is different between countries. For instance, one senior interviewee from region 2 highlighted the case of WRC-07 where the issue of IMT identification in the C-band was discussed. At the time of WRC-07, the band was already allocated to mobile services but not identified as IMT. The European 
countries wanted to have the band identified as IMT and the opposing countries wanted to place restrictions on IMT in order to protect the other services operating in the band. In particular, countries of region 2 did not want to have restrictions on the use of the band as it is already allocated to mobile service. Therefore, they decided not to have the band identified as IMT while still using it for IMT due to the presence of existing mobile allocation.

It is worth mentioning that several interviewees highlight some deficiencies associated with the process of having part of the spectrum identified for IMT, although there may not be related to the regulators' decision on technology selection. Firstly, it is difficult and takes a long time to obtain agreement on IMT identification through WRCs. The case of IMT identification has encouraged other technology developers to seek identification (for example, High Altitude Platform Stations (HAPS)). Another difficulty is that while the first IMT identified bands were fully harmonised, it has become more difficult to find harmonised bands throughout the world considering the increasing number of identified bands. In particular, it has become uneconomical to have radio equipment that can support this large number of frequency bands. In fact, there is a large opportunity costs for manufacturers when they consider the need to incorporate extra frequency bands in a mobile handset (GSMA, 2007).Identification is also considered as a barrier for emerging technologies, as identification gives less incentive for manufacturers to be innovative and produce equipment that works across a wider range of frequencies.

IMT identification is considered as disadvantageous to other radiocommunication services that do not want the IMT to get their spectrum. As explained by one of the interviewees "a lot of people think that commercial mobile industry is very arrogant and does not need as much spectrum as they keep asking for, and so there is a backlash against the identification to IMT'. In particular, many entities participate in the ITU-R discussion to restrict IMT access to spectrum (that has for example being allocated to satellite and broadcasting services). Additionally, one interviewee raised an interesting point related to the competition of IMT with other radiocommunication service: IMT identification is not considered by many as identifying particular technologies. Instead, it is like a service allocation where you can use IMT technologies. As one interviewee explained: "it is like saying we think that spectrum is identified for the commercial mobile service, or a commercial mobile application, and you can use IMT technologies". This was confirmed by one senior interviewee who is involved in the WP 5D activities, who argued that IMT is not strictly identification for a technology because IMT is not only technology but also services vision. Another noticeable observation by one of the interviewees is that the IMT identification could be perceived as an allocation to a combined service of fixed, mobile, and broadcasting.

Figure 6 illustrates how IMT spectrum identification has a different but positive influence on the decisions of regulators regarding the selection of technologies from the IMT family (concepts 84, 8, 90, 85, 86, 87, 88, 89, 91). However, it was noted that such an impact is dependent on the country (concept 12). 


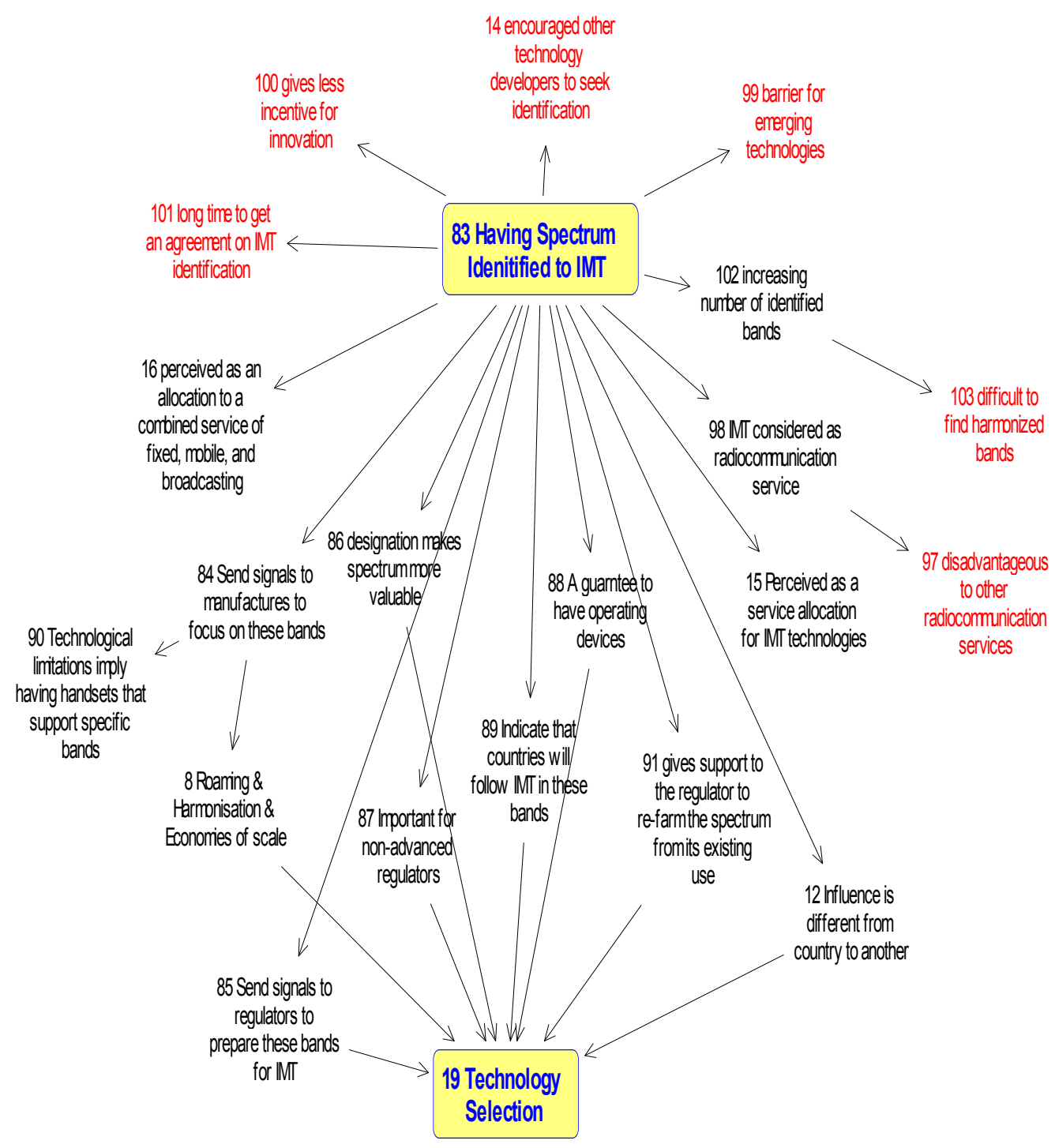

Figure 6: Influence of IMT Spectrum Identification on Regulator Decision on Technology Selection

In addition, several more general observations emerged from the interviews. Firstly, IMT spectrum identification may have a negative influence on new technologies and on innovation (concept 99, 100). Secondly, within the ITU-R, reaching agreement on identification is difficult (concept 101) and other technologies related to other services rather than mobile have started to seek identification and not only service allocation (concept 14). The increasing amount of spectrum for IMT has made harmonisation more difficult (concept 103). One observation made was that IMT identification is perceived by some as an allocation to a radiocommunication service rather than just identification of a technology (concept 15).

Moreover, such allocation is envisioned as multiple allocations to fixed, mobile and broadcasting rather than just an allocation to a mobile service (concept 
16). In other words, it could be argued that IMT identification enables more flexibility in service allocation as it accommodates elements from three main services (fixed, mobile and broadcasting). Furthermore, the issue that IMT spectrum identification is disadvantageous to other radiocommunication services (concept 97) could be perceived as supporting the argument that IMT identification implies deploying IMT even if the band has other service allocations.

Regarding the influence of IMT spectrum identification on regulators, there were two views among 12 interviewees. The first view held by four interviewees is that identification does not negatively influence technology neutrality. In particular, IMT identification does not preclude other uses of the spectrum. There is no restriction on re-farming to other technologies because in the same part of the spectrum, the technology will be similar whether the band is identified for IMT or not. Furthermore, there was an influence of IMT identification on removing the link between technology and spectrum that used to be. In particular, there use to be a link where GSM operate in the $900 \mathrm{MHz}$ and $3 \mathrm{G}$ was linked to the $2 \mathrm{GHz}$ band. Regarding mobile technology in the L-Band as SDL, while the band is not yet identified as being part of IMT and only allocated to mobile services, it is not necessary to wait for WRC-15 to confirm this identification. Instead, work was already commended in standardisation organisations such as 3GPP (Marks, Lavender, \& Wongsaroj, 2015). This may show how mobile development is not limited to IMT spectrum identified bands.

On the other hand, there were several negative comments concerning the influence of IMT spectrum identification by eight interviewees. Firstly, one difficulty for IMT identification is that it is considered as disadvantageous for other mobile use in the identified bands rather than IMT (for example, TETRA - IBurst). More specifically, it becomes only possible for non-IMT technologies to be deployed in non-IMT identified bands. Evidence of this is that non-IMT technologies were proposed in bands not identified for IMT. For instance, IBurst technology, which was proposed in the duplex gap of the $1800 \mathrm{MHz}$ where there is no IMT equipment. However, IBurst was not able to outperform IMT technologies. Therefore, it was argued that any proprietary technology would not be able to compete in the market against IMT technologies regardless of the regulator decisions.

Furthermore, linking spectrum to IMT may restrict re-farming. More specifically, it could be considered as an 'excuse' to be used by regulators not to apply technology neutrality and to limit the use of a particular band to exclusively IMT. In addition, it was pointed out also that having the band identified for IMT would mean an implicit use for LTE in the future. This was confirmed by a senior interviewee from Africa, who argued that although some regulators may be neutral having the IMT technologies with all its advantages motivates them to pick IMT. One senior interviewee from the mobile industry argued that while there is no relationship between applying technology neutral and having IMT spectrum identification, having such identification encourages regulators to identify the band for IMT. In other words, the spectrum identification process focuses the attention on IMT solutions as opposed to alternative technologies even if such identification does not preclude other uses.

One senior interviewee from the mobile industry also argued that IMT identification would imply using the band for IMT. For instance, regarding the 700 $\mathrm{MHz}$ allocation, there was a suggestion to allocate the band to mobile service without 
IMT identification so it would not give signals that the spectrum is moving from broadcasters to mobile operators. This highlights the major influence of IMT identification and the difference from normal mobile service allocation as it largely implies using IMT.

Regarding the influence on technology neutrality, there are several perceived elements, both positive and negative, that have an influence on technology neutrality. These are shown in Figure 7. Having spectrum identified to IMT largely implies using the spectrum for IMT, which could discourage regulators from applying technology neutrality and to limit the band use to only IMT (concepts 106, 105, 96, 107, 108, 13). On the other hand, such identification does not preclude other mobile use (concepts 92, 93) and mobile development has been progressed in bands other than those identified for IMT (concept 95). Moreover, the IMT spectrum identification was felt by interviewees to positively contribute to the introduction of technology neutrality (concept 94). This leads to the conclusion that IMT spectrum identification has a positive impact on regulatory decisions towards selecting technologies from the IMT family. However, the extent of such influence is dependent on the country and IMT spectrum identification has elements of both flexibility and restriction on the concept of technology neutrality.

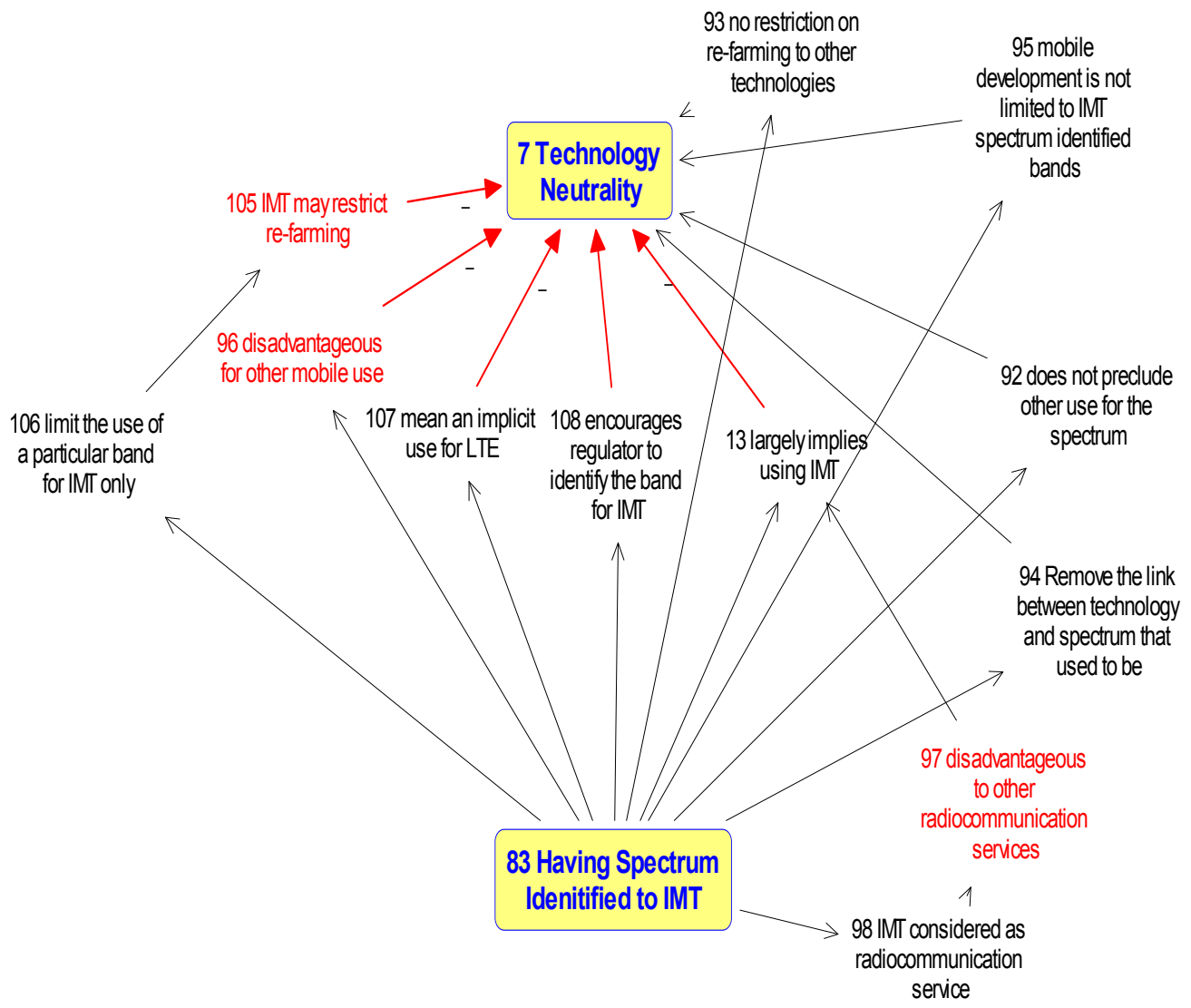

Figure 7: Influence of IMT Spectrum Identification on Regulator Decision on Technology Neutrality 


\section{Conclusions}

The analysis of the data collected from the interviews in this paper has demonstrated that IMT standardisation activities do not prevent the adoption of technology neutrality. However, there are different elements of support and opposition that have an influence on the regulator's stance towards technology neutrality. These elements are dependent on a country's geographical position, its perceptions towards technological neutrality, the size of country's market, its level of technological advancement, interpretation of international regulations, and the status of the national telecommunication market.

As the main purpose of the research is to explore these elements due to the qualitative nature of the research and the interpretivism philosophical position of the researcher, it was not preferable to identify the dominant ones among them. In addition, identifying a dominant influence would require having different type of data collection method preferably quantitative and would be only applicable to specific case studies. This is due that the IMT standardisation process may have different influence according to the country per se. For instance, while in some countries the ITU regulations are part of the law, in others, they only acknowledge it.

With respect to the paper's first research question, on the influence of IMT standardisation on technology selection and technology neutrality nationally, the analysis of the interviews has shown the following. Firstly, being part of the IMT family of standards provides support to the applicant technologies. However, there is another view that being an IMT technology is a second priority to other factors that have a greater influence on regulator decision on technology.

It was also found that IMT standardisation has positive (accommodating), negative (restrictive), and neutral elements in terms of the influence on the regulator's decision regarding technology neutrality. The first view is that there are elements of IMT standardisation that encourage more neutrality in technology selection, and the IMT family of standards is considered to be in conformity with technology neutrality. The second view is that the IMT standardisation may discourage regulators from being neutral, and may have a negative influence on operators and technology developers, while the third view is that IMT standardisation does not have an influence on the adoption of technology neutrality.

With respect to the paper's second question which focused on the influence of IMT standardisation on perspectives regarding mobile technology generations definition, the analysis has shown that while one view is that there is mutual influence between the IMT definitions and definitions of $3 \mathrm{G}$ and $4 \mathrm{G}$, as alternative view is that there is no influence because the ITU-R has taken several actions to diminish any influence of IMT standards on the technology generations definitions used in the market.

Regarding the third question we investigated, namely, the influence of IMT standardisation on discrimination between mobile technology generations, the interviewees expressed the view that IMT standardisation has mostly no influence on the discrimination between technology generations nationally. This is because regulators differentiate between technology generations due to reasons related to the telecommunication market circumstances nationally rather than because of reasons 
related to IMT. Moreover, the ITU-R has undertaken several actions to reduce the variation between IMT-2000 and IMT-Advanced and not to be involved in the discussion related to the differentiation between $3 \mathrm{G}$ and $4 \mathrm{G}$. However, regulators could use the IMT-2000 and IMT-Advanced labels to justify discrimination between technologies nationally.

With regard to the paper's final question, which explored the influence of IMT spectrum identification on technology selection and technology neutrality, it was evident that such identification has a positive impact on a regulator's decision towards selecting technologies from the IMT family. However, the extent of such influence is dependent on the country. In particular, identification makes spectrum more valuable, and having a particular spectrum band identified for IMT gives support to the regulator to re-farm the spectrum from its existing use. In additional, it was revealed that IMT spectrum identification has elements of flexibility and restriction on the concept of technology neutrality. Firstly, restrictive elements, including having spectrum identified to IMT, may imply using the spectrum for IMT. This, in turn, may discourage regulators from applying technology neutrality and to limit the band use to IMT only instead. Secondly, flexible elements include that such identification does not preclude other mobile use and that mobile development has been progressed in bands other than those identified for IMT.

In general, the research has examined the perceptions of what is regarded to be technology neutrality in the context of IMT considering that almost all technologies are part of the IMT family. Therefore, even if a regulator is neutral, most probably the winning technology would be IMT. This raises a question of whether being neutral within IMT can be considered to be full neutral or not?

Another issue to be clarified is that the purpose of this paper was not to explore the concept of technology neutrality in general. Instead, the main context of the paper is IMT and selecting technologies from or outside the IMT technologies. Having said that, the interviews with national regulators have revealed that there is no solid agreement on what is meant by technology neutrality in general and it has different indications according to the regulator background, being from developed or developing country, licensing conditions, market structure and other elements that are outside the scope of this paper.

An area for future research could be examining the influence of IMT standardisation process on the decline of technologies such as WiMAX. Anther area that is worth examination is the effect of IMT discussion within the ITU on that the emergence of one dominant standard in the $4 \mathrm{G}$ era, namely, LTE. The data used in the analysis could be broadened through including interviews with a wider range of interviewees from across a broadly defined telecommunications industry. Other methodologies such as discourse analysis could also be drawn on to enhance the analysis and track how the views of stakeholders change over time.

Furthermore, the results of the research could be shared with the interviewees to further examine the findings and to get their feedbacks. However, this was considered to be difficult due to the large number of interviewees and the limitation in the time for conducting the research. Quantitative measures could be also applied to extend the number of stakeholder on the international and national level. For instance, a survey could be sent to all of the ITU-R countries to spread the examination to other countries. Moreover, the discussion in WRC-19 on identifying more frequencies for 
IMT and the evaluation of new technologies to be part of the IMT-2020 family would shed more light on the influence of IMT standardisation and spectrum identification on regulators' decision on technology selection.

\section{References}

Albino, V. (2003). Cognitive Maps and Sustainable Development in the Mediterranean region. In D. Camarda \& L. Grassini (Eds.), Local Resources and Global Trades: Environments and Agriculture in the Mediterranean Region. Bari: CIHEAM.

Ali, R. (2009). Technological Neutrality Lex Electronica, 14(2), 1-15.

Anker, P., \& Lemstra, W. (2011). Governance of Radio Spectrum: License Exempt Devices. In W. Lemstra, V. Hayes, \& J. Groenewegen (Eds.), The Innovation Journey of Wi-Fi: The Road to Global Success: Cambridge University Press.

Bazeley, P. (2007). Qualitative Data Analysis with NVivo (2nd edn.). London: Sage.

Bekkers, R. (2001). Mobile Telecommunications Standards: GSM, UMTS, TETRA, and ERMES. Norwood: Artech House.

Besen, S. M., \& Farrell, J. (1991). The Role of the ITU in Standardization: Preeminence, Impotence or Rubber Stamp? Telecommunications Policy, 15(4), 311-321.

Bohlin, E. (2012). Technology Neutrality - Why Europe Got on Board. Paper presented at the International Roundtable Discussion on a Technology Neutral Spectrum Regime in the Indonesian Cellular Business, Jakarta.

Brodkin, J. (2013). Qualcomm's global LTE chip could help end iPhone fragmentation. Ars Technica. Retrieved from https://arstechnica.com

Bryman, A., \& Bell, E. (2007). Business research methods. New York: Oxford University Press.

Callendar, M. H. (1994). Future Public Land Mobile Telecommunication Systems (FPLMTS). Paper presented at the The Third Annual International Conference on Universal Personal Communications, San Diego,.

Cave, M. (2002). Review of Radio Spectrum Management, An Independent Review for Department of Trade and Industry and HM Treasury. Retrieved from www.ofcom.org.uk

Cave, M., Doyle, C., \& Webb, W. (2007). Essentials of modern spectrum management. Cambridge ; New York: Cambridge University Press.

Cave, M., Foster, A., \& Jones, R. W. (2006). Radio Spectrum Management: Overview and Trends. Paper presented at the ITU Workshop on Market Mechanisms for Spectrum Management, Geneva, Swiss. http://www.itu.int

Chaduc, J., \& Pogorel, G. (2008). The Radio Spectrum.Managing a Strategic Resource. London: ISTE Ltd.

Codding, G. A. (1991). Evolution of the ITU. Telecommunications Policy, 15(4), 271285.

Codding, G. A., \& Rutkowski, A. M. (1982). The International Telecommunication Union in a Changing World. Washington: Artech House.

Cowhey, P. F., Aronson, J. D., \& Richards, J. E. (2008). The Peculiar Evolution of 3G Wireless Networks. In W. J. D. a. E. J. Wilson (Ed.), Governing Global Electronic Networks: International Perspectives on Policy and Power: MIT Press.

Curwen, P. (2004). Has GSM won the technology war? Info, 6(1). 
Eden, C. (2004). Analyzing Cognitive Maps to Help Structure Issues or Problems. European Journal of Operational Research, 159(3), 673-686.

Eden, C., \& Ackermann, F. (1998). Analysing and Comparing Idiographic Causal Maps. In C. Eden (Ed.), Managerial and Organisational Cognition. London: Sage.

El-Moghazi, M., Whalley, J., \& Irvine, J. (2015). Influence of IMT Standardisation Process on

WiMAX Decline. Paper presented at the Second Regional ITS Conference, New Delhi. Engelman, R. B. (1998). Keynote Address. Paper presented at the PCIA'S Coming of Age: $3 \mathrm{G}$ Spectrum Conference

Foster, A. (2008). Spectrum Sharing. Paper presented at the GSR 2008, Thailand.

Freyens, B. P. (2009). A Policy Spectrum for Spectrum Economics. Information Economics and Policy, 21(2), 128-144.

Frullone, M. (2007). A Deeper Insight in Technology and Service Neutrality. Paper presented at the ITU Workshop on Market Mechanisms for Spectrum Management, Geneva.

Funk, J. L. (1998). Competition between Regional Standards and the Success and Failure of Firms in the World-Wide Mobile Communication Market. Telecommunications Policy, 22(4-5), 419-441.

Goldman, D. (2010). 4G is a myth (and a confusing mess). Retrieved from http://money.cnn.com

GSMA. (2007). The Advantages of Common Frequency Bands for Mobile Handset Production. Retrieved from www.gsma.com

Hazlett, T. W. (2001). The Wireless Craze, The Unlimited Bandwidth Myth, The Spectrum Auction Faux Pas, and the Punchline to Ronald Coase's "Big Joke": An Essay on Airwave Allocation Policy. Harvard Journal of Law \& Technology, 13(2), 335-469.

Indepen and Aegis Systems. (2004). Costs and Benefits of Relaxing International Frequency Harmonisation and Radio Standards. Retrieved from stakeholders.ofcom.org.uk

ITU. (1997). WRC-97 News. WRC News. http://www.itu.int/

ITU. (1998). The ITU Takes Mobile into the Third Millennium. Press Release. Retrieved from http://www.itu.int/

ITU. (2008). Development of IMT-Advanced: The SMaRT Approach. Press Release. Retrieved from http://www.itu.int/

ITU. (2010a). ITU Paves Way for Next-Generation 4G Mobile Technologies. Press Release. Retrieved from http://www.itu.int/

ITU. (2010b). ITU World Radiocommunication Seminar highlights future communication technologies [Press release]. Retrieved from www.itu.int

ITU. (2012). IMT-Advanced Standards for Mobile Broadband Communications. Press Release. Retrieved from http://www.itu.int/

ITU. (2017a). Futuristic mobile technologies foresee "IMT for 2020 and beyond. Retrieved from www.itu.int

ITU. (2017b). ITU agrees on key 5G performance requirements for IMT-2020 [Press release]. Retrieved from $\underline{w w}$.itu.int

ITU-R. (1997). ITU-R Recommendation M.687-2: International Mobile Telecommunications-2000 (IMT-2000). In $M$ Series. Mobile, Radiodetermination Amateur and Related Satellite Services.

ITU-R. (2001a). Article 5: Frequency Allocations. In WRC-2000 Final Acts. 
ITU-R. (2001b). WRC-2001 Resolution 223: Additional Frequency Bands Identified for IMT. In Provisional Final Acts - World Radiocommunication Conference (WRC-2000).

ITU-R. (2007a). ITU-R Recommendation M.1822: Framework for Services Supported by IMT. In M Series. Mobile, Radiodetermination Amateur and Related Satellite Services.

ITU-R. (2007b). Resolution ITU-R 57: Principles for the Process of Development of IMT-Advanced. Paper presented at the Radiocommunication Assembly (RA07). www.itu.int

ITU-R. (2007c). WRC-07 Resolution 223: Additional Frequency Bands Identified for IMT. In Provisional Final Acts - World Radiocommunication Conference (WRC-07).

ITU-R. (2008). Article 5: Frequency Allocations. In Radio Regulations (Vol. 1).

ITU-R. (2009). ITU-R Recommendation M.1457-8: Detailed Specifications of the Radio Interfaces of International Mobile Telecommunications-2000 (IMT2000). In M Series. Mobile, Radiodetermination Amateur and Related Satellite Services.

ITU-R. (2010). ITU-R Report SM.2093-1: Guidance on the Regulatory Framework for National Spectrum Management.

ITU-R. (2012a). Article 5: Frequency Allocations. In Radio Regulations: 2012 Edition (Vol. 1).

ITU-R. (2012b). ITU-R Recommendation M.2012: Detailed Specifications of the Terrestrial Radio Interfaces of International Mobile Telecommunications Advanced (IMT-Advanced). In $M$ Series. Mobile, Radiodetermination Amateur and Related Satellite Services.

ITU-R. (2012c). WRC-12 Resolution 232. Use of the Frequency 694-790 MHz by the Mobile, Except Aeronautical Mobile, Service in Region 1 and Related Studies. In Provisional Final Acts - World Radiocommunication Conference (WRC-12).

ITU-R. (2015a). Article 5: Frequency Allocations. In Radio Regulations (Vol. 1).

ITU-R. (2015b). ITU-R Recommendation M.2012-2: Detailed Specifications of the Terrestrial Radio Interfaces of International Mobile Telecommunications Advanced (IMT-Advanced). In $M$ Series. Mobile, Radiodetermination Amateur and Related Satellite Services.

ITU-R. (2015c). Provisional Final Acts - World Radiocommunication Conference (WRC-15).

ITU-R. (2016). Invitation for Submission of Proposals for Candidate Radio Interface Technologies for The Terrestrial component of The Radio Interface(s) for IMT-2020 and Invitation to Participate in Their Subsequent Evaluation. Retrieved from www.itu.int

ITU-R. (2017). ITU-R Recommendation M.1457-13: Detailed Specifications of the Radio Interfaces of International Mobile Telecommunications-2000 (IMT2000). In M Series. Mobile, Radiodetermination Amateur and Related Satellite Services.

ITU-R Working Party 5D. (2017). DRAFTNEW REPORT ITU-R M.[IMT-2020.TECH $P E R F$ REQ] Minimum requirements related to technical performance for IMT-2020 radio interface(s). Paper presented at the The 26th meeting of WP 5D, Geneva. 
Kamecke, U., \& Korber, T. (2006). Technological Neutrality in the EC Regulatory Framework for Electronic Communications: A Good Principle Widely Misunderstood. E.C.L.R.(5).

Kelly, G. (1955). The Psychology of Personal Constructs. New York: Norton.

Leite, F., Engelman, R., Kodama, S., Mennenga, H., \& Towaij, S. (1997). Regulatory considerations relating to IMT-2000. IEEE Personal Communications, 4(4), 14-19.

London Economics. (2008). Economic Impacts of Increased Flexibility and Liberalisation in European Spectrum Management: Report for A Group of European Communications Sector Companies. Retrieved from http://londoneconomics.co.uk/

Lovells, H. (2014). Technology Neutrality in Internet, Telecoms and Data Protection Regulation Global Media and Communications, Autumn(14), 19-23.

Maitra, A. (2004). Wireless Spectrum Management. Policies, Practices, and Conditioning Factors: The McGraw-Hill Companies.

Marks, P., Lavender, T., \& Wongsaroj, S. (2015). Global Momentum and Economic Impact of the $1.4 / 1.5 \mathrm{GHz}$ band for IMT. Retrieved from www.plumconsulting.co.uk

McLean Foster \& Co. (2013). Study of Market-based Exclusive Spectrum Rights. Retrieved from http://www.ic.gc.ca/

Miles, M. B., \& Huberman, A. M. (1994). Qualitative Data Analysis: An Expanded Sourcebook. USA: Sage Publications.

Newlands, M. (2009). World's Biggest Mobile Market Rejects Technology Neutrality. PolicyTracker. Retrieved from https://www.policytracker.com

OECD. (2006). The Spectrum Dividend: Spectrum Management Issues. Retrieved from www.oecd.org

Osseiran, A. (2013). The 5G Mobile and Wireless Communications System. Paper presented at the ETSI Future Mobile Summit.

Padilla, J., Davies, J., \& Boutin, A. (2017). Economic Impact of Technology Standards. Retrieved from

Pansera, M., \& Owen, R. (2015). Framing resource-constrained innovation at the 'bottom of the pyramid': Insights from an ethnographic case study in rural Bangladesh. Technological Forecasting and Social Change, 92, 300-311.

Pogorel, G. (2007). Opinion: The Nine Regimes of Spectrum Management". PolicyTracker. Retrieved from www.policytracker.com

Prigenta, M., Fontenellea, G., Rochetb, M.-J., \& Trenkelb, V. M. (2008). Using Cognitive Maps to Investigate Fishers' Ecosystem Objectives and Knowledge. Ocean \& Coastal Management, 51(6).

Saugstrup, D., \& Henten, A. (2006). 3G Standards: the battle between WCDMA and CDMA2000. Info, 8(4), 10-20.

Savage, J. (1989). The Politics of International Telecommunications Regulation. London: Westview Press.

Sims, M. (2005). Move Towards Technology Neutrality. PolicyTracker.com. Retrieved from https://www.policytracker.com

Sims, M. (2006). Europe Divided, Asia Takes the Lead. PolicyTracker.com. Retrieved from https://www.policytracker.com

Sims, M. (2007). Geneva ITU Meetings Increase Flexibility for Mobile. PolicyTracker. Retrieved from https://www.policytracker.com

Topcu, I. (2014). Cognitive Maps. Decision Making Techniques Lecture Notes. Retrieved from http://web.itu.edu.tr/ 
U.S. Congress Office of Technology Assessment. (1993). The 1992 World Administrative Radio Conference: Technology and Policy Implications.

Wellenius, B., \& Neto, I. (2005). The Radio Spectrum: Opportunities and Challenges for the Developing World. Retrieved from

Whittaker, M. (2002). True Technology Neutral Spectrum Licences. Retrieved from www.futurepace.com.au

WIMAXForum. (2007). WiMAX and IMT-2000. Retrieved from http://www.wimaxforum.org

WP 5D Chairman. (2009). Chapter 01 - Working Party 5D Chairman's Report. Paper presented at the Meeting of Working Party 5D (Dresden, 14 to 21 October 2009), Geneva. www.int.itu

Xia, J. (2011). The third-generation-mobile (3G) policy and deployment in China:

Current status, challenges, and prospects. Telecommunications Policy, 35(1), 51-63.

Yuanyuan, W., \& Shikui, W. (2016). Managing ambidexterity in creative industries: A survey. Journal of Business Research, 69(7), 2388-2396.

Ziegler, C. (2011a). 2G, 3G, 4G, and everything in between: an Engadget wireless primer. Engadget. Retrieved from https://www.engadget.com/

Ziegler, C. (2011b). AT\&T: both HSPA+ and LTE are '4G,' 20 such devices planned for this year. Retrieved from www.engadget.com 